Article

\title{
Analysis of Relationship between Road Geometry and Automated Driving Safety for Automated Vehicle-Based Mobility Service
}

\author{
Sehyun Tak ${ }^{1, *(\mathbb{D})}$, Sari Kim ${ }^{1}$, Hwapyeong Yu ${ }^{2} \mathbb{D}$ and Donghoun Lee ${ }^{1} \mathbb{1}$ \\ 1 Center for Connected and Automated Driving Research, The Korea Transport Institute, Sejong 30147, Korea; \\ sarikim@koti.re.kr (S.K.); donghoun.lee@koti.re.kr (D.L.) \\ 2 Department of Civil and Environmental Engineering, Korea Advanced Institute of Science and Technology, \\ Daejeon 34141, Korea; yhp7237@kaist.ac.kr \\ * Correspondence: sehyun.tak@koti.re.kr; Tel.: +82-44-211-3134
}

check for

updates

Citation: Tak, S.; Kim, S.; Yu, H.;

Lee, D. Analysis of Relationship

between Road Geometry and

Automated Driving Safety for

Automated Vehicle-Based Mobility

Service. Sustainability 2022, 14, 2336.

https://doi.org/10.3390/su14042336

Academic Editors: Efthimios Bothos,

Panagiotis Georgakis, Babis

Magoutas and Michiel de Bok

Received: 5 January 2022

Accepted: 14 February 2022

Published: 18 February 2022

Publisher's Note: MDPI stays neutral with regard to jurisdictional claims in published maps and institutional affiliations.

Copyright: () 2022 by the authors Licensee MDPI, Basel, Switzerland. This article is an open access article distributed under the terms and conditions of the Creative Commons Attribution (CC BY) license (https:// creativecommons.org/licenses/by/ $4.0 /)$.

\begin{abstract}
Various mobility services have been proposed based on the integration of automated vehicle (AV) and road infrastructure. Service providers need to identify a set of road sections for ensuring the driving safety of an AV-based mobility service. The main objective of this research is to analyze the safety performance of $\mathrm{AVs}$ on the road geometrical features present during this type of mobility service. To achieve the research goal, a mobility service is classified by a combination of six road types, including expressway, bus rapid transit (BRT) lane, principal arterial road, minor arterial road, collector road, and local road. With any given road type, a field test dataset is collected and analyzed to assess the safety performance of the AV-based mobility service with respect to road geometry. Furthermore, the safety performances of each road section are explored by using a historical dataset for human-driven vehicle-involved accident cases. The result reveals that most of the dangerous occurrences in both $\mathrm{AV}$ and human-driven vehicles show similar patterns. However, contrasting results are also observed in crest vertical curve sections, where the AV shows a lower risk of dangerous events than that of a human-driven vehicle. The findings can be used as primary data for optimizing the physical and digital infrastructure needed to implement efficient and safe AV-based mobility services in the future.
\end{abstract}

Keywords: mobility service; automated vehicle; driving safety; road geometrical feature; human-driven vehicle

\section{Introduction}

Many strategies have been investigated (1) to address the limitations of current public bus transport, such as low service quality and profitability, and (2) to satisfy requirements for new mobility services, such as mobility-as-a-service and ride-hailing [1-4]. One of the best alternatives to reduce labor costs and operational inefficiency for a mobility service is to incorporate an automated vehicle (AV) system into public transport [5]. For instance, Navya operates an automated driving shuttle service in Sion, Switzerland, servicing 25 locations. In Bad Birnbach, Germany, EasyMile runs an automated shuttle service linking train stations and downtown areas. AV-based public transport services increase customer convenience by linking them with the existing public transport system, thereby effectively reducing waiting time, traffic volume, and road congestion [6].

Most previous research has forecasted that the traffic flow capacity would be increased by employing an AV system [7-11]. However, the results from actual driving environments suggest otherwise. In particular, a commercially available adaptive cruise control (ACC) for the AV produced a longer headway than that of a human-driven vehicle [12,13], which may often result in a capacity drop [14]. It was also observed that the speed fluctuation of the preceding vehicle was amplified and transmitted to the following vehicle [15]. The 
performance of lane-keeping systems (LKS) in AVs also varies with vehicle type, and AVs performed poorly on curves and hills [16]. The American Automobile Association also conducted a similar test on public roads and found that $73 \%$ of $\mathrm{AV}$ system malfunctions involved the LKS [17]. Major malfunctions included "abrupt disengagement", "erroneous disengagements in terms of perceived inattention", "ping-ponging within the lane", and "becoming uncomfortably close to other vehicles or guardrails in the lateral direction", especially on curved roads. The system was also affected by sunlight and lane type.

Accordingly, there has been growing interest in the road geometry and environmental conditions for automated vehicles to drive safely. The SAE J3016 defines operational design domains (ODD) as "operating conditions under which a given driving automation system or feature thereof is specifically designed to function" [18]. Level 5 automated vehicles have unlimited ODD, but they do not yet exist. Level 4 controls itself without fallback to the driver even in dangerous situations, but it is operated only in limited spaces. Level 3, the level of the complete object, event detection, and response (OEDR), requests fallback to the driver when it escapes from the ODD, and the scope of ODD varies differently depending on the definition of the dynamic driving task (DDT). Since perfect OEDR is not performed below level 2, continuous concentration by the driver is required [18]. SAE J3016 does not provide the exact feature of ODD at each automated level due to the wide range of possible ODDs and possible features. The ODD cannot be defined collectively, and it inevitably varies depending on the DDT and driving area given the mobility condition. Therefore, when designing a mobility service accompanied by automated driving, the DDT and driving area should be defined first, and the ODD should be designed based on numerous actual driving tests. For example, AVs should be able to recognize lanes on curved roads at high speed and perform well under different environmental brightness conditions [19]. The ODDs for AV-based public transport include intersections and pedestrian crossings, and its DDTs involve pedestrian recognition, signal recognition, and intersection turns [20].

On the other hand, traditional mobility service requires a three-step planning process [21-23]. First, the new mobility service area is selected based on a customer demand survey; second, the mobility service type is identified; and third, the appropriate route for the service type is created, the road infrastructure for operation is repaired, and vehicles are deployed. However, because the service areas for AV-based mobility (AVM) are limited, differences exist in steps 2 and 3 of the traditional mobility service planning process. The AVM's service area shall be determined after investigating the road infrastructure and environmental condition. The service provider decides whether automated vehicles can be operated in that area. Thereafter, suitable services are provided considering the route, passenger access method, and dispatch interval in the defined path of the automated vehicles. Nevertheless, the roads where the AVs cannot be operated are excluded even if the AVM services are required in that route [20]. Current AVM services are implemented by only determining whether the service can be provided under specific conditions, without considering the ODDs that make automated driving possible. Therefore, it is impossible to develop measures to determine (1) what type of services can be provided based on the road type and (2) what road design modifications are needed to introduce or expand the automated driving-based mobility services. Hence, the passenger satisfaction for AV-based services and the efficiency of service providers are, inevitably, low.

The aims of this study are twofold: (i) to analyze the safety performance of AVs on various road types and geometrical features from the perspective of mobility services and (ii) to identify mobility requirements for developing new AV technologies. The remainder of this paper is organized as follows. Section 2 describes the methodology and dataset used in this research. Section 3 presents the result and analysis. Finally, Section 4 concludes the paper with additional considerations for further research.

\section{Methodology}

Figure 1 shows the safety analysis framework for an AVM service. To analyze the driving conditions for the AVM, services and roads were classified and field tests were used 
to assess each service. The safety-related incidents for AVMs were analyzed using field test data and correlated with the road geometry. The results were compared with accident factors for vehicles with a human driver. Automated driving field test data were used to classify the geometrical features of the dangerous sections for automated driving based on the classification and regression tree (CART) model. Finally, the dangerous event patterns of automated vehicles and accident patterns of drivers for each group derived from the CART model were compared and analyzed.

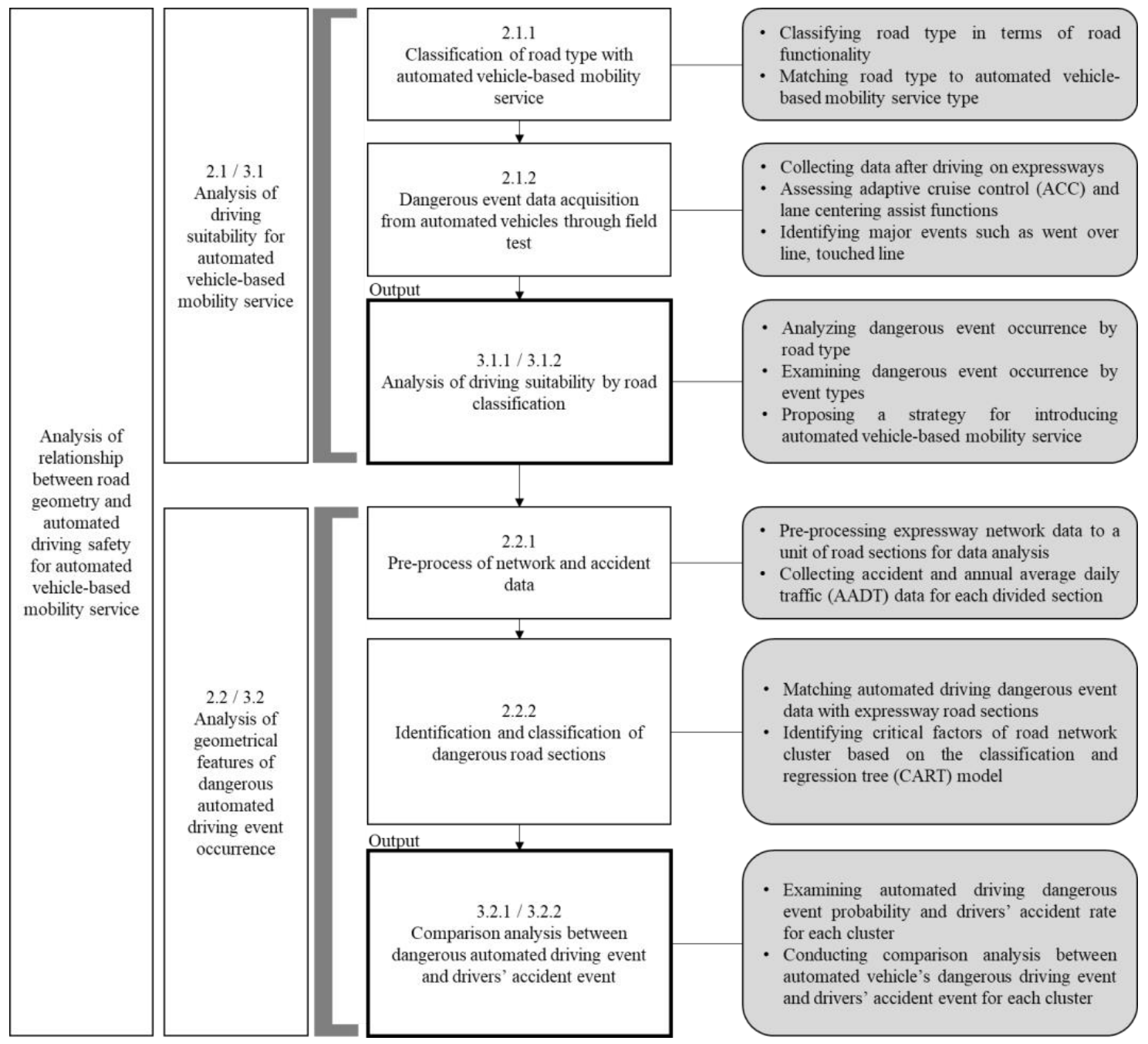

Figure 1. Framework of driving safety analysis for automated vehicle-based mobility (AVM) service.

\subsection{Driving Suitability Analysis Method}

\subsubsection{Classifying Roads by AVM Service}

Roads are classified into six types depending on the purpose and function $[24,25]$. For each classified road type, the occurrence trend of dangerous events was analyzed by performing a field test with the automated vehicle.

Figure 2 shows the road types classified according to use. Expressways enable highspeed driving and have the smallest longitudinal slopes and curves among the classified roads. Bus Rapid Transit (BRT) lanes are designed for efficient driving of buses without mixing with other vehicles. Principal arterial roads handle mass transit traffic between major areas within cities and counties, or between cities and counties, thus forming the framework of a city or county. Minor arterial roads connect principal arterial roads with collector roads or major traffic sources, thus allowing city or county traffic to gather and scatter and form the outskirts of neighborhood residential areas. Collector roads connect 
the traffic of neighborhood residential areas with minor arterial roads, thus allowing traffic in neighborhood residential areas to gather and scatter and divide the inside of the neighborhood residential areas. Local roads divide households (a group of areas surrounded by roads).

(a) Expressway

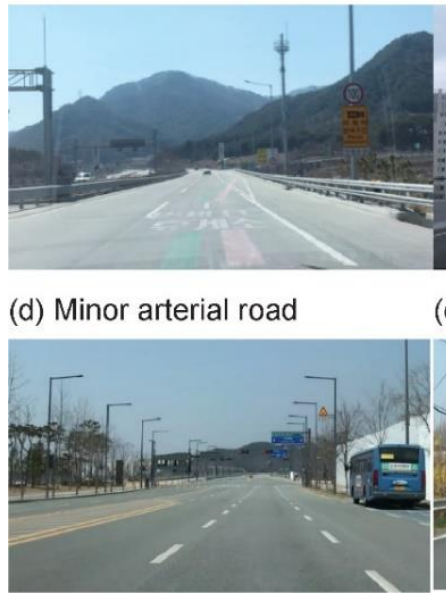

(b) BRT Lane

(c) Principal arterial road

Figure 2. Types of roads.

Table 1 matches the road type with the AVM service type [26]. It is evident that S1 operates on BRT lanes and expressways; $\mathrm{S} 2$ operates on expressways and principal arterial roads; and S3 operates on expressways, principal arterial roads, and minor arterial roads. S4 operates on principal arterial and minor arterial roads; S5 operates on principal arterial, minor arterial, and collector roads; and S6 is operated on collector and local roads. Lastly, S7 operates on all roads except the BRT lane.

Table 1. Matching road and service types.

\begin{tabular}{|c|c|c|c|c|c|c|c|c|}
\hline \multicolumn{9}{|c|}{ Service Type } \\
\hline & & $\begin{array}{c}\text { S1 } \\
\text { AV } \\
\text { Fixed-Route } \\
\text { Transit } \\
\text { Service } \\
\text { (Dedicated) }\end{array}$ & $\begin{array}{c}\text { S2 } \\
\text { AV } \\
\text { Fixed-Route } \\
\text { Transit } \\
\text { Service (Non- } \\
\text { Dedicated) }\end{array}$ & $\begin{array}{c}\text { S3 } \\
\text { AV } \\
\text { On-Demand } \\
\text { Transit } \\
\text { Service } \\
\text { (Group) }\end{array}$ & $\begin{array}{c}\text { S4 } \\
\text { AV } \\
\text { On-Demand } \\
\text { Transit } \\
\text { Service } \\
\text { (By-Pass) }\end{array}$ & $\begin{array}{c}\text { S5 } \\
\text { AV Paratransit } \\
\text { (On-Demand): } \\
\text { Urban }\end{array}$ & $\begin{array}{c}\text { S6 } \\
\text { AV Paratransit } \\
\text { (On-Demand): } \\
\quad \text { (Rural) }\end{array}$ & $\begin{array}{c}\text { S7 } \\
\text { AV Taxi }\end{array}$ \\
\hline \multirow{4}{*}{$\begin{array}{l}\text { Road } \\
\text { Type }\end{array}$} & BRT Lane & $\bigcirc$ & & & & & & \\
\hline & Expressway & 0 & 0 & 0 & & & & $\bigcirc$ \\
\hline & $\begin{array}{l}\text { Principal } \\
\text { arterial }\end{array}$ & & O & 0 & 0 & 0 & & 0 \\
\hline & $\begin{array}{l}\text { Minor arterial } \\
\text { Collector } \\
\text { Local }\end{array}$ & & & $\bigcirc$ & $\bigcirc$ & $\begin{array}{l}\bigcirc \\
\bigcirc\end{array}$ & $\begin{array}{l}\bigcirc \\
0\end{array}$ & $\begin{array}{l}0 \\
\bigcirc \\
0\end{array}$ \\
\hline
\end{tabular}

\subsubsection{Obtaining Dangerous Event Data from Automated Vehicles through Field Tests}

The road types were tested for automated driving suitability. The field test driving area comprised $2977.13 \mathrm{~km}$ of expressways, which is $62 \%$ of the total length of expressways in South Korea. The datasets are available at https://github.com/dhleeGDH/Fieldtest_da taset_for_AV (accessed on: 31 January 2022).

Figure $3 \mathrm{~b}$ shows the driving areas with BRT lanes, principal arterial, minor arterial, collector, and local roads involving $77 \mathrm{~km}$ of roads around Sejong City, South Korea. The BRT lane, principal arterial roads, and minor arterial roads achieved high driving performance results because they were constructed recently, whereas the collector and local roads are typical roads in the old town and suburbs. 


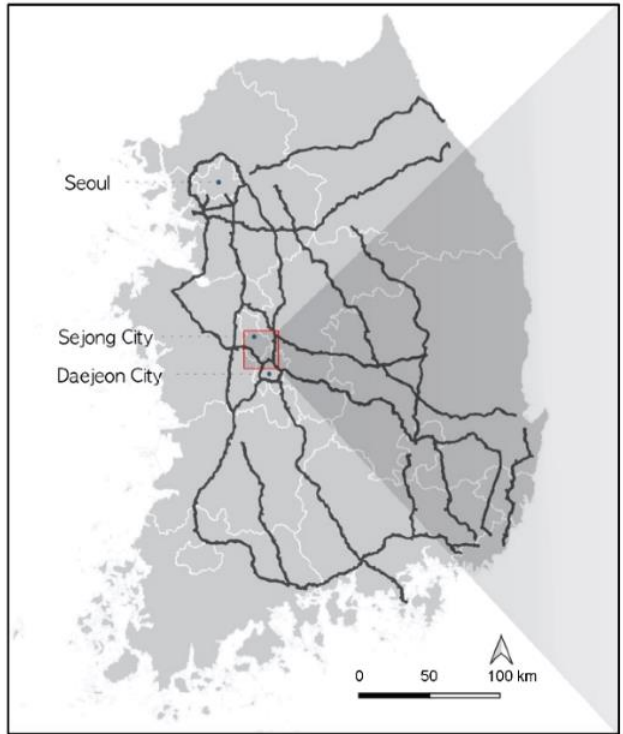

(a) Field test area: expressway

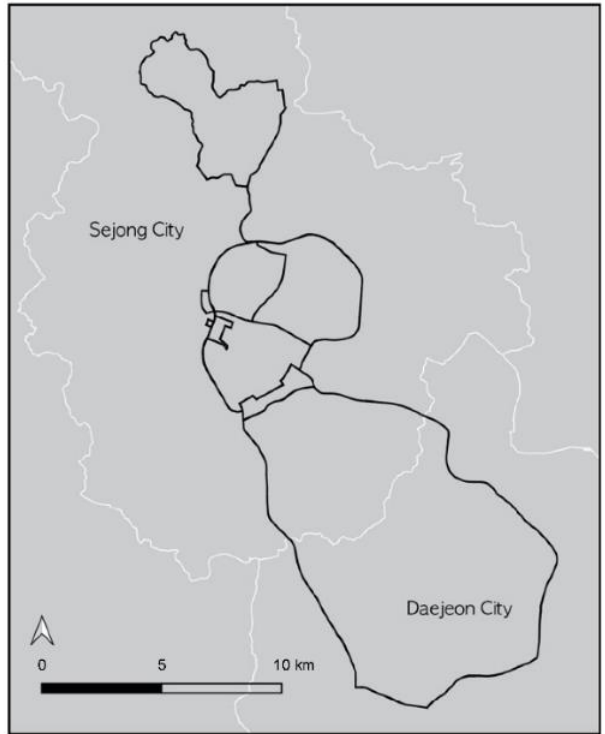

(b) Field test area: bus rapid transit (BRT) lane principal arterial, minor arterial, collector, and local road (enlarged area marked by the red box in a)

Figure 3. Driving areas for field tests of automated vehicles.

Dangerous driving event is herein defined by AV system malfunctions such as ACC and lane-centering failures. ACC functions are often turned off by a significant perturbation induced by the road geometry, such as a sharp slope or curve. Similarly, due to the geometric road design, the lane-centering functions usually fail, resulting in touching the line and/or going over the line. The details can refer to the on-line datasets described earlier.

\subsection{Geometrical Features of the Dangerous Event Occurrence}

\subsubsection{Preprocessing the Network and Accident Data}

The source data, such as geometrical features, required for the risk analysis of automated vehicles and the correlation analysis of the road geometry were extracted from the expressway network data from the Korea Expressway Corporation. This data comprised three primary variables: longitudinal slope, horizontal alignment, and number of lanes. In addition, the changes in longitudinal slope and curve radius values were generated as properties of each link and were calculated by subtracting the longitudinal slope/curve radius values of the current link from the longitudinal slope/curve radius values of the previous link. These two consecutive links were in the direction of vehicle movement.

The expressway data we used were constructed for building, maintaining, and managing expressways. Hence, the changes in the longitudinal slope and curve radius occur within a single link. Therefore, the expressway network data were preprocessed before the correlation analysis, so that a single link had homogeneous properties. Hence, the values of the horizontal alignment, curve radius, longitudinal slope, and number of lanes for one link did not change. For example, when a road link changed from a straight to a curved section, we divided it into two links: a straight road and a curved road.

Driving accident data from 2011 to 2017 from the Korea Expressway Corporation were used, which included the date of the accident, time, expressway route name, postmile, and number of accidents [27]. The accident occurrence rate for each link was calculated using the following equation $[22,28]$ :

$$
\text { Accident occurrence rate for general vehicles }=\sum \frac{(\text { Number of Accidents })}{(\text { Length of section } \times A A D T)},
$$


where the annual average daily traffic (AADT) is the annual traffic volume divided by 365 days for a specific segment [29]. The AADT data were obtained from the expressway public data portal.

\subsubsection{Identifying and Classifying the Dangerous Road Sections}

Automated driving dangerous occurrence data were generated based on the driving image data collected during the field test in Section 2.1.2. To analyze the geometrical features of dangerous road sections, the automated driving dangerous occurrence data were matched with the expressway network data preprocessed in Section 2.2.1 based on the expressway postmile.

The geometrical properties of the dangerous section were analyzed by matching data using the CART model $[30,31]$. The CART model was chosen because it can analyze both nominal and continuous variables [31,32].

The CART model classifies the dataset by minimizing impurities using the Gini index $(G) . G$ is calculated using the following formula [33]:

$$
G=\Sigma\left(1-P_{k}^{2}\right),
$$

where $P$ is the proportion of samples belonging to class $k$, and $k$ represents $m$ classes of the target variable $(k=1,2,3, \ldots, \mathrm{m})$. $G$ ranges between 0 and 1 , and the impurity increases as $G$ approaches 0.5 . The CART model branches out the decision tree when the impurity of $G$ is minimum based on the input variables [31]. The input variables of this model are the longitudinal slope, horizontal alignment, curve length, curve radius, number of lanes, change in the longitudinal slope, change in the curve length, and change in the number of lanes. The output variable is the occurrence of dangerous events with an automated vehicle.

\section{Results}

\subsection{Driving Suitability Result and Analysis for AVM Service}

\subsubsection{Analyzing Dangerous Event Occurrence by Road Type}

Figure 4 shows the dangerous occurrences for AVs by road type. Dangerous situations occurred once every $7.3 \mathrm{~km}, 1.8 \mathrm{~km}$, and $6.9 \mathrm{~km}$ on average on expressways, BRT lanes, and principal arterial roads, respectively, showing higher safety than other road types. Minor arterial and collector roads exhibited relatively low safety with one dangerous situation per $1.1 \mathrm{~km}$ and $0.55 \mathrm{~km}$, respectively. Local roads yielded poor performance such that the test was impossible because lane markings were lost or not clear. The test results indicate that implementing AVM services on expressways will be the easiest and safest followed by on principal arterial roads.

Figure 5 shows the frequency of occurrence of two dangerous situations-went overthe-line and touched-the-line- by road type. On expressways, the automated driving function worked best because expressway geometry was designed to change smoothly. Going over-the-line occurred once every $264 \mathrm{~km}$ on average, and these events often occurred in sharp curves and in confluence sections where the geometry changed abruptly. Touchedthe-line occurred once every $8 \mathrm{~km}$ on average. It occurred when lanes were drawn in double, in slightly sharp curves, and in sections with uneven road surfaces. Furthermore, instability in controlling the vehicle occurred from repetitive touch-line events in sections with excessively wider lanes than general lanes and grooved surface sections. Overall, the expressway is the most feasible road type for applying AVM services at the current technology level of automated driving. 


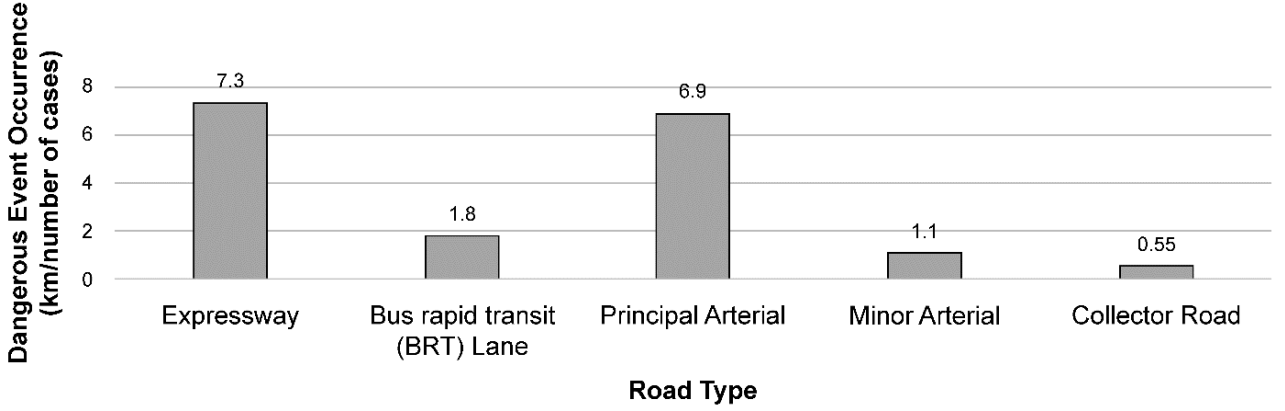

Figure 4. Dangerous event occurrence by road type.

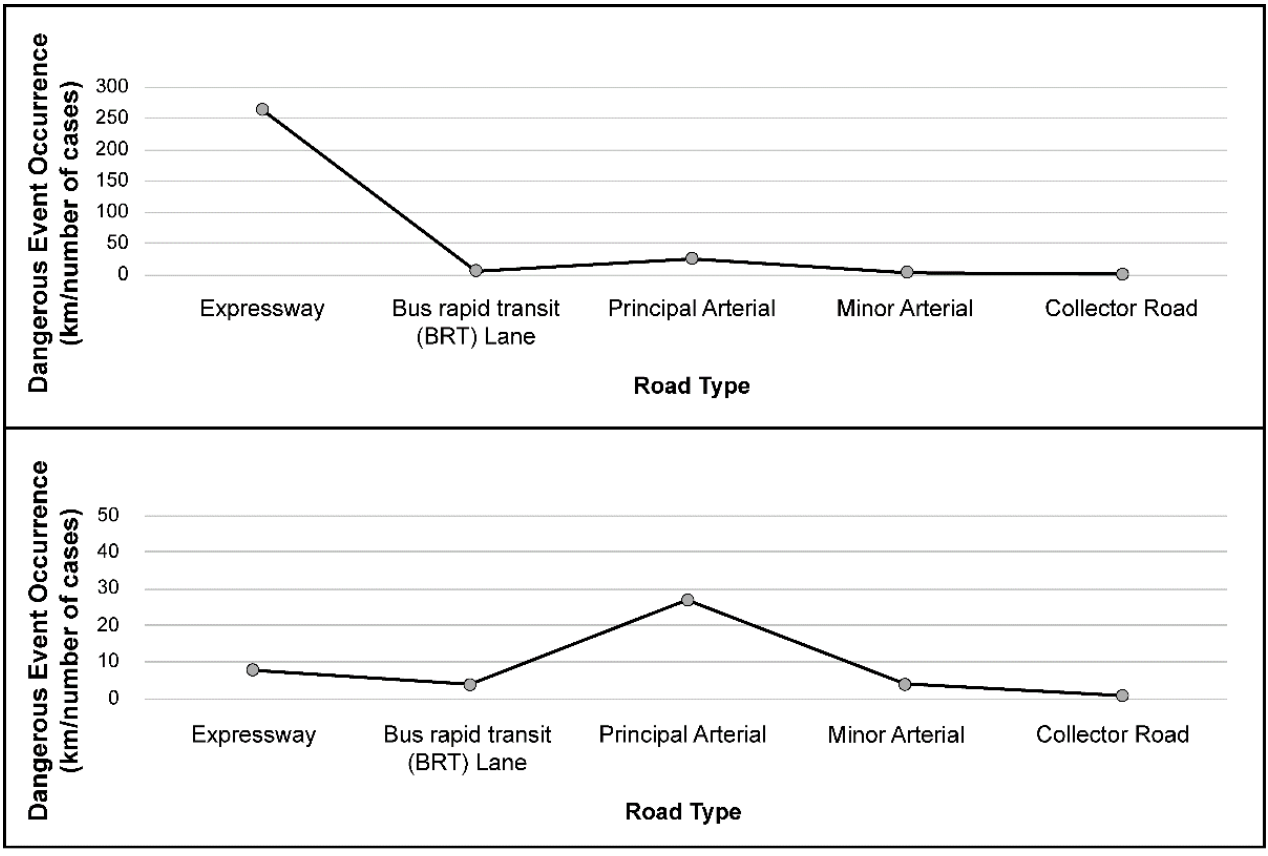

Figure 5. Dangerous event occurrences for automated driving by road type.

In BRT lanes, an over-the-line event occurred once every $6 \mathrm{~km}$ on average, whereas touched-the-line occurred once every $4 \mathrm{~km}$ on average. The factors that lower the safety of BRT lanes include the narrow lane width compared to the size of the bus, abrupt changes in geometry at merging and diverging areas, and sudden slopes at the entry and exit of bridges and underpasses. In contrast, principal arterial roads achieved the second-best driving safety results next to expressways, with one went over-the-line per $27 \mathrm{~km}$ on average and one touched-the-line per $27 \mathrm{~km}$ on average. The dangerous events on principal arterial roads occurred in sharp curved sections and sections with narrow lane widths, similar to those on expressways. However, the driving safety performance on principal arterial roads was poorer than on expressways because sharp curves were encountered more frequently.

Minor arterial roads showed driving safety similar to that of BRT lanes, with one went over-the-line and one touched-the-line per $5 \mathrm{~km}$ and $4 \mathrm{~km}$ on average, respectively. Minor arterial roads yielded low driving performance due to frequent sharp curves and abrupt road width changes. Collector roads showed low driving safety, with one went over-theline per $2 \mathrm{~km}$ on average, and one touched-the-line per $1 \mathrm{~km}$ on average. This is due to the poor lane marking and road conditions. Lastly, local roads were almost impossible to drive on because there were no lanes. Thus, many technological improvements are required to introduce automated driving-based services. 


\subsubsection{Proposing a Strategy for Introducing the AVM Service}

Considering the driving performance of automated vehicles by service type it is crucial to establish strategies for implementing each type of service. In the case of S1, the AV service could be introduced sooner if some sections are improved particularly those with abrupt changes in road geometry due to topographical limitations. The S2 service can be promptly applied if the existing cooperative intelligent transport systems (C-ITS) infrastructure or low-level precision maps to automate route setting and stopping at stations are used. The current geometries of expressways and principal arterial roads are highly suitable for automated driving. For S3 and S4 services, new C-ITS infrastructure and high-precision maps should be used. The results of the field test show that introducing these services on minor arterial roads is limited under the current automated driving technology due to abrupt changes in road geometries, uneven road widths, high traffic density, and steep longitudinal slope sections. In addition to the improvement of the physical infrastructure, the introduction of S3 and S4 services on minor arterial roads requires the construction of a digital infrastructure and the provision of active safety support services.

S5 services can be implemented even on arterial and collector roads with low automated driving suitability. Particularly, on arterial and collector roads, AVM services could be introduced only if limiting factors such as poor lane conditions, illegal parking, sharp curves in narrow road widths, obstacles and pedestrians, and speed bumps are mitigated. Technologies that enhance safety, such as dynamic maps and C-ITS, must be adopted. In addition, to provide demand-response services, it is also crucial to improve customer convenience by exploiting cloud computing and urban integrated information technology.

For S6 services, automated driving is almost impossible on the current roads. Therefore, instead of providing public transport services to all underserved areas, it will be more advantageous for rapid commercialization to set major routes for S6 services and construct digital infrastructure based on these major routes. Since underserved areas will remain, where the cost of building the digital infrastructure for AVM offsets the benefits of operating an AVM service, it will be necessary to first construct major service routes and then gradually expand the services strategically. Finally, S7 service appears to be the most challenging as it aims to operate on all roads. Consequently, to quickly introduce S7 service, it will be advantageous to establish major routes and secure profitability and safety before gradually expanding the application areas.

\subsection{Geometrical Features of Dangerous AV Driving Event Occurrence \\ 3.2.1. Analyzing the AV Dangerous Driving Events}

Figure 6 shows the relationship between the occurrence of dangerous events and road geometry based on the CART model. The input variables were the longitudinal slope, horizontal alignment, curve length, curve radius, number of lanes, change in longitudinal slope, change in curve length, and change in the number of lanes. The target variable was the occurrence of dangerous events in the road test results. Based on the CART analysis, 15 groups were classified by the Gini index as described in Equation (2). Among the straight roads, Group 1 included the most downhill roads whereas Group 2 included the most uphill roads. Downhill roads were found to be slightly more dangerous than uphill roads. Curved roads were classified into Groups 3-15. Generally, the smaller the curve radius and the longer the curve are, the higher the incidence of dangerous situations. Group 3 had a very small curve radius but a low probability of dangerous events because the curve was very short. This indicates that even in sharp-curved sections, automated vehicles can drive safely if the length of the curve is not long. Groups 4 to 9 include geometries characterized by many small sharp curved sections with a small curve radius. The results verified that safe automated driving is possible with the tested AV technology, even in sharp curved sections, unless it is a steep uphill road. Groups 10 to 15 include geometries with a gentle longitudinal slope area and large curve radius. Group 14, whose probability of dangerous events occurring is 0.444 , includes a sharp uphill section with a longitudinal slope of $2.591 \%$ 
grade (approximately $1.484^{\circ}$ ) or higher. Group 8, which includes a sharp uphill section, also has a high probability of dangerous events occurring.

The overall trend shows that more dangerous events occurred in sections that are characterized by a curved part with a small curve radius and an uphill slope (Groups 14, 10, 4,8 , and 6 ). Fewer dangerous events occurred in sections characterized by nearly straight or downhill curved parts (Groups 5, 7, 12, 3, and 15).

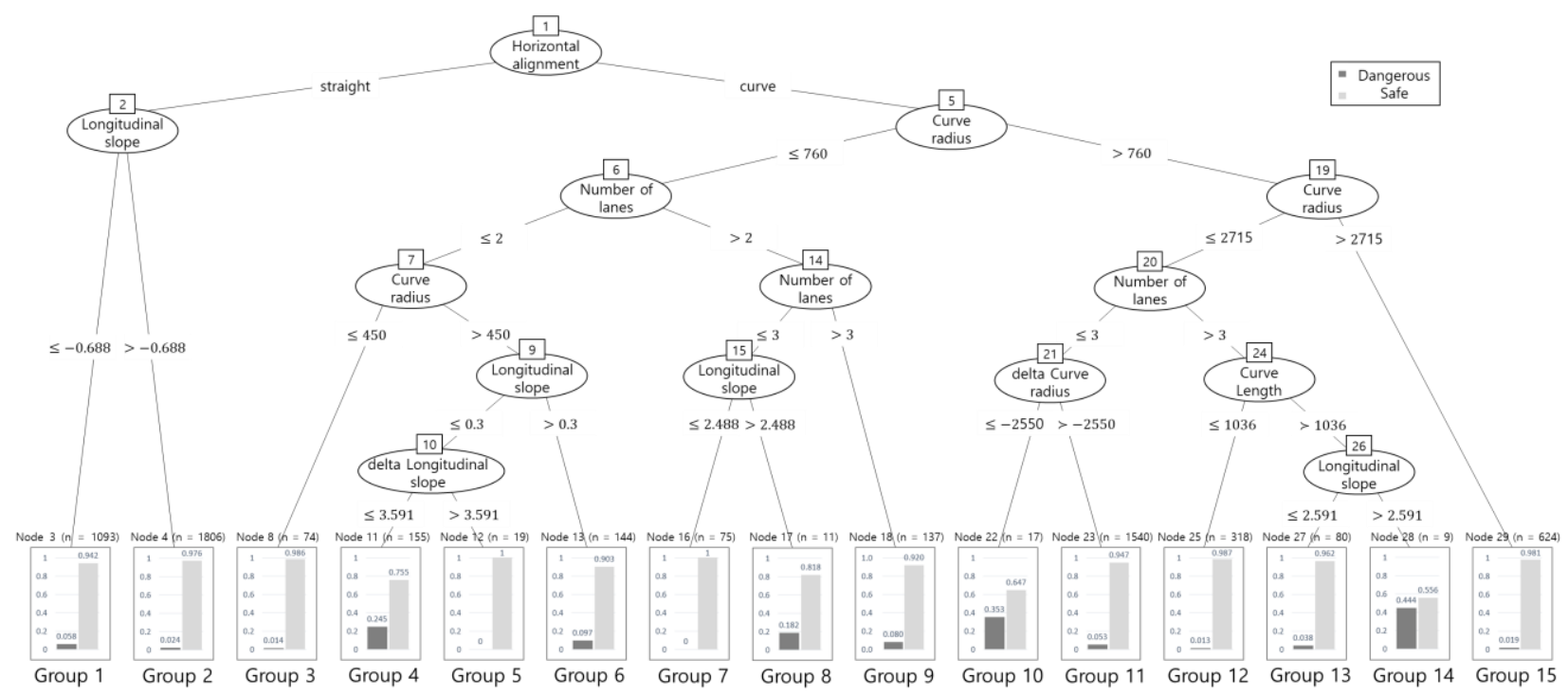

Figure 6. Automated driving dangerous event probability for each road network cluster based on the classification and regression tree (CART) model.

\subsubsection{Comparing Dangerous AV Driving Events with Driver Accident Events}

Based on the combinations of geometrical features, we filter the historical dataset, as described in the Section 2.2.1 earlier, and calculate the AADTs and accident rates of each Group. Figure 7 shows the probability of driver accidents for each group classified by the danger probability of automated vehicles. Groups 4, 5, and 14 had the highest probabilities of accidents. Groups 4 and 5 include downhill sections with a sharp curve radius that can limit the driver's vision. Thus, their accident rates were high [34]. Group 14 is a gently curved road with a sharp uphill section. In particular, this section includes a curved section that is longer than $1 \mathrm{~km}$. This indicates that a curved uphill section with a long curve has a high accident rate due to a delay in recognizing front objects [35].

Based on Figures 6 and 7, the results in AV and human-driven vehicles are summarized in Table 2. As shown in Table 2, the driving accident rate was relatively high in Groups 4 and 14, where the automated vehicle was considered to be dangerous. Group 5 showed a low probability of dangerous events occurring for AV but with a high human driver accident rate. Group 5 is a downhill road with sharp curved sections, but the direction of the slope change is opposite to that of Group 4. In the case of drivers, accidents often occur because of limited visibility going uphill on sharp curved sections. Nevertheless, AVs can drive more safely on a road where the longitudinal slope shifts significantly from uphill to downhill [36]. Since the height of the vision sensor from the ground is normally greater than that of driver's eye, AVs are usually able to prevent dangerous events.

Similarly, in the case of Group 11, when the curve suddenly changed from gentle to sharp, human-driven vehicles show a high accident rate due to visual perception errors, whereas AVs can identify the road environment and steer the vehicle more accurately. On the other hand, as shown in the result of Group 8, which indicates a three-lane uphill road with a sharp curved section, there is a relatively low human driver accident rate; whereas, the AV shows a high probability of dangerous events due to the limited sight distance in the crest vertical curve. 


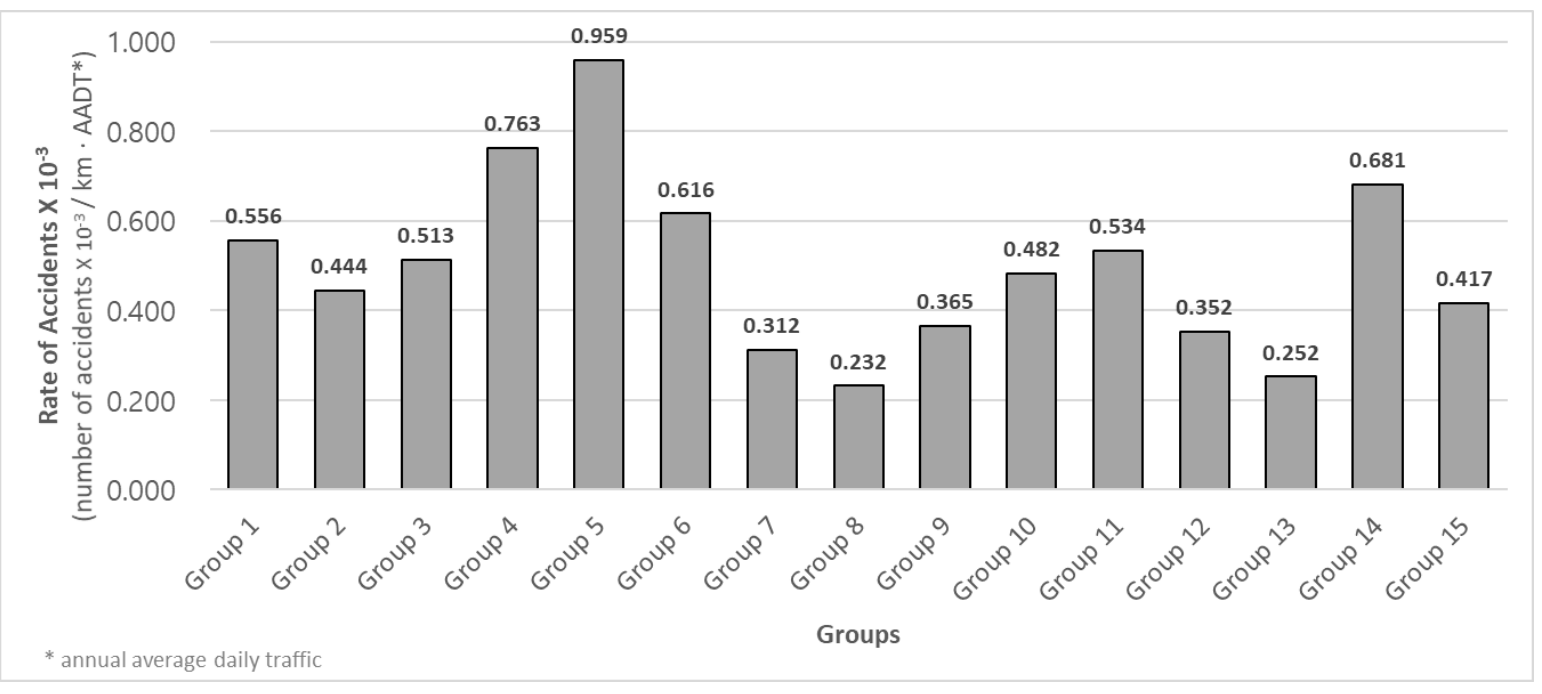

Figure 7. Accident rate of general vehicles for each road network cluster based on the classification and regression tree (CART) model.

Table 2. Summary of results in AV and human-driven vehicles.

\begin{tabular}{ccc}
\hline & $\begin{array}{c}\text { AV } \\
\text { (Prob. of Dangerous Event) }\end{array}$ & $\begin{array}{c}\text { Human-Driven Vehicle } \\
\text { (Rate of Accidents) }\end{array}$ \\
\hline Group 1 & 0.058 & 0.556 \\
Group 2 & 0.024 & 0.444 \\
Group 3 & 0.014 & 0.513 \\
Group 4 & 0.245 & 0.763 \\
Group 5 & 0 & 0.959 \\
Group 6 & 0.097 & 0.616 \\
Group 7 & 0 & 0.312 \\
Group 8 & 0.182 & 0.232 \\
Group 9 & 0.080 & 0.365 \\
Group 10 & 0.353 & 0.482 \\
Group 11 & 0.053 & 0.534 \\
Group 12 & 0.013 & 0.352 \\
Group 13 & 0.038 & 0.252 \\
Group 14 & 0.444 & 0.681 \\
Group 15 & 0.019 & 0.417 \\
\hline
\end{tabular}

\subsection{Discussion}

The research findings in the present study agree with the previous studies [37,38], which have focused on exploring the relationship between geometric road design and potential collision risk, particularly in road geometry with a crest vertical curve. With the pre-determined risk factors related to road geometry, mobility service providers shall comprehensively make the decision for providing the AVM service based on the spatial distribution of road safety classification. The following shows the details of the application to the road safety classification.

Figure 8 shows the mapping results of dangerous sections in South Korean expressways. The red, yellow, and green sections in the figure represent the expressway sections where both AVs and drivers, only drivers, and only AVs were found to be dangerous, respectively; the blue sections represent roads where both drivers and AVs were found to be safe. Figure 8a shows the north- and west-bound expressways, which have a total length of $4821.2 \mathrm{~km}$. The total length of the red sections, corresponding to Groups 4 and 14, was $219.2 \mathrm{~km}$ or $4.5 \%$ of the network. The total length of the yellow sections was $9.1 \mathrm{~km}$ or $0.2 \%$ of the network. The total length of the green sections was $1483.1 \mathrm{~km}$ or $30.6 \%$ of the network. Figure $8 \mathrm{~b}$ shows the south- and east-bound roads, which have a total length of 
$4705 \mathrm{~km}$. In the south- and east-bound roads, the total length of the sections for which both AVs and drivers, only drivers, and only AVs were found to be dangerous were $128.7 \mathrm{~km}$ $(2.7 \%), 6.4 \mathrm{~km}(0.1 \%)$, and $1058.7 \mathrm{~km}(22.5 \%)$, respectively.

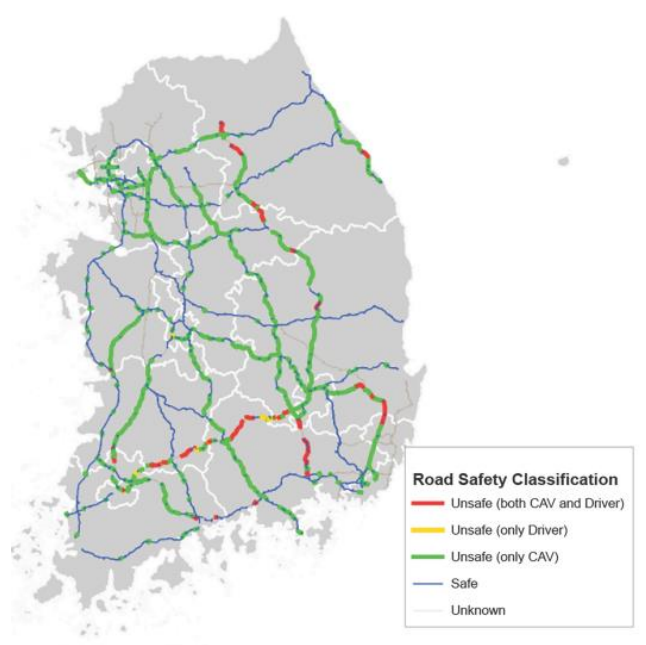

a) North-and west-bound

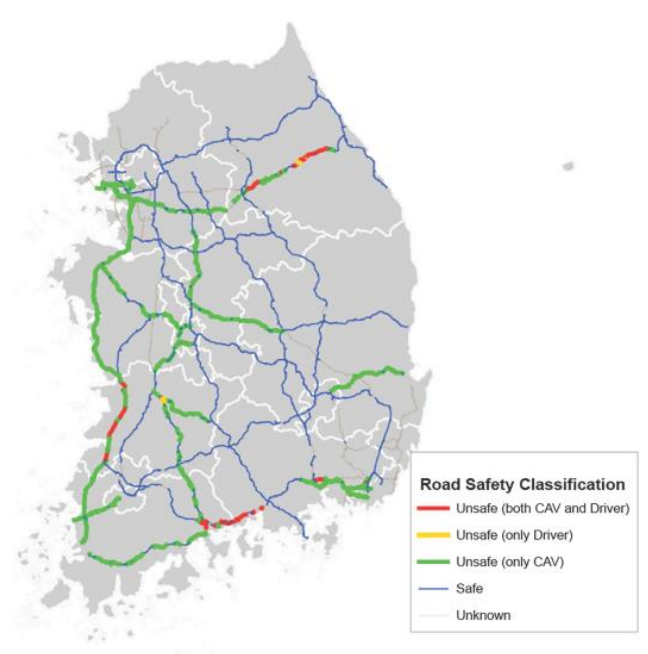

b) South- and east-bound

Figure 8. Road safety classification of the entire South Korean expressway.

These results suggest that current AVs have a higher probability to be exposed to vulnerable sections compared to human-driven vehicles. In other words, decision makers can prioritize the spatial area for the AVM service to avoid nullifying the positive effects of AV functions.

\section{Conclusions}

The main objective of this study was to analyze the safety performance of AV on road geometrical feature given type of mobility service. To achieve the research objective, the mobility service was classified by a combination of six road types, including expressway, BRT lane, principal arterial road, minor arterial road, collector road, and local load. The combinations of road types were considered to indirectly reflect the characteristics of the given mobility service.

With that assumption, we explored the relationship between automated driving safety and given road type based on field test dataset. The result showed that expressways, BRT lanes, and principal arterial roads were very safe for AVs. In contrast, the minor arterial and collector roads limited the safe driving of AVs due to abrupt changes in road geometries and infrequent road maintenance. Local roads were poorly suited to AVs; thus, it is necessary to improve the road geometries and actively utilize the digital infrastructure to introduce automated driving safely and efficiently.

Furthermore, the relationship between the road geometry and the probability of dangerous events occurring for AVs on expressways was analyzed and compared with the driving accident rates. The results showed that automated driving had a higher probability of dangerous incidents in curved sections than in straight sections. These consequences were due to various combinations of the geometries, such as the curve radius and longitudinal slope. The probability of dangerous events occurring for AVs revealed similar trends to human driving accident rates in general. On the other hand, an AV was much safer than a human-driven vehicle, particularly on uphill slopes since drivers were relatively more vulnerable to visual errors induced by such conditions. These research findings suggest that it can be utilized for primary data to facilitate the physical and digital infrastructure, which will uprate the safety performance of AVM service in the near future.

This study determined the automated driving suitability and the characteristics of dangerous road sections, but the following matters need to be considered for further research. First, additional static road risk factors that influence automated driving on 
various roads need to be investigated. The present study derived the characteristics of automated driving dangerous sections merely for expressways. To this end, other static road environment factors present in other road types such as intersections, crosswalks, and narrow lanes should be investigated. Second, the automated driving risk factors analysis should also include dynamic environmental conditions, such as weather, vehicle traffic, and illuminance. We experienced a situation where the automated vehicle continuously deviated from the lanes due to heavy rain in the dark on a straight road during a field test. This shows that automated driving functions are also significantly affected by dynamic environmental conditions. We plan to include dynamic conditions in our analysis through simulations or field tests in a controlled environment in future studies. Furthermore, additional analysis on the driving safety of $\mathrm{AVs}$ will be conducted with other available datasets for containing heterogeneity types of vehicles in further research. Other types of eco-friendly mobility services, such as electric vehicles [39], can also be considered in future studies.

Author Contributions: Conceptualization, S.T. and S.K.; methodology, S.T. and H.Y.; software, S.T. and S.K.; validation, S.T.; formal analysis, S.T. and D.L.; investigation, S.K.; resources, S.T. and S.K.; data curation, S.T. and S.K.; writing — original draft preparation, S.T. and S.K.; writing —review and editing, D.L.; visualization, S.K. and H.Y.; supervision, S.T.; project administration, S.T. All authors have read and agreed to the published version of the manuscript.

Funding: This research was supported by the National Research Council for Economics, Humanities and Social Sciences and the Korea Transport Institute under the Strategy of Digitalization of Road Network for Connected and Automated Driving Research Project (Grant No. 21-22-014).

Institutional Review Board Statement: Not applicable.

Informed Consent Statement: Not applicable.

Data Availability Statement: The data supporting the findings of this study are available within the article.

Conflicts of Interest: The authors declare no conflict of interest.

\section{References}

1. Shaheen, S.; Bansal, A.; Chan, N.; Cohen, A. Mobility and the Sharing Economy: Industry Developments and Early Understanding of Impacts. 2017. Available online: https:/ / escholarship.org/uc/item/96j5r729 (accessed on 13 February 2022).

2. Stocker, A.; Shaheen, S. Shared Automated Mobility: Early Exploration and Potential Impacts. Road Veh. Autom. 2018, 4, 125-139.

3. Lazarus, J.; Shaheen, S.; Young, S.E.; Fagnant, D.; Voege, T.; Baumgardner, W.; Fishelson, J.; Lott, J.S. Shared Automated Mobility and Public Transport. Road Veh. Autom. 2018, 141-161. [CrossRef]

4. Stark, K.; Gade, K.; Heinrichs, D. What does the future of automated driving mean for public transportation? Transp. Res. Rec. 2019, 2673, 85-93. [CrossRef]

5. Iclodean, C.; Cordos, N.; Varga, B.O. Autonomous shuttle bus for public transportation: A review. Energies 2020, $13,2917$. [CrossRef]

6. Tak, S.; Woo, S.; Park, S.; Kim, S. The City-Wide Impacts of the Interactions between Shared Autonomous Vehicle-Based Mobility Services and the Public Transportation System. Sustainability 2021, 13, 6725. [CrossRef]

7. Wang, J.; Rajamani, R. The impact of adaptive cruise control systems on highway safety and traffic flow. Proc. Inst. Mech. Eng. Part D J. Automob. Eng. 2004, 218, 111-130. [CrossRef]

8. Van Arem, B.; Van Driel, C.J.; Visser, R. The impact of cooperative adaptive cruise control on traffic-flow characteristics. IEEE Trans. Intell. Transp. Syst. 2006, 7, 436. [CrossRef]

9. Zhao, J.; Oya, M.; El Kamel, A. A safety spacing policy and its impact on highway traffic flow. In Proceedings of the 2009 IEEE Intelligent Vehicles Symposium, Xi'an, China, 3-5 June 2009; pp. 960-965.

10. Talebpour, A.; Mahmassani, H.S. Influence of connected and autonomous vehicles on traffic flow stability and throughput. Transp. Res. Part C Emerg. Technol. 2016, 71, 143-163. [CrossRef]

11. Yu, H.; Tak, S.; Park, M.; Yeo, H. Impact of autonomous-vehicle-only lanes in mixed traffic conditions. Transp. Res. Rec. 2019, 2673, 430-439. [CrossRef]

12. Makridis, M.; Mattas, K.; Ciuffo, B. Response time and time headway of an adaptive cruise control. An empirical characterization and potential impacts on road capacity. IEEE Trans. Intell. Transp. Syst. 2019, 21, 1677-1686. [CrossRef]

13. Makridis, M.; Mattas, K.; Anesiadou, A.; Ciuffo, B.; OpenACC. An open database of car-following experiments to study the properties of commercial ACC systems. Transp. Res. Part C Emerg. Technol. 2021, 125, 103047. [CrossRef] 
14. Shang, M.; Stern, R.E. Impacts of commercially available adaptive cruise control vehicles on highway stability and throughput. Transp. Res. Part C Emerg. Technol. 2021, 122, 102897. [CrossRef]

15. Makridis, M.; Mattas, K.; Ciuffo, B.; Re, F.; Kriston, A.; Minarini, F.; Rognelund, G. Empirical study on the properties of adaptive cruise control systems and their impact on traffic flow and string stability. Transp. Res. Rec. 2020, 2674, 471-484. [CrossRef]

16. Insurance Institute for Highway Safety IIHS Examines Driver Assistance Features in Road, Track Tests. 2018. Available online: https://www.iihs.org/news/detail/iihs-examines-driver-assistance-features-in-road-track-tests (accessed on 13 February 2022).

17. American Automobile Association. Evaluation of Active Driving Assistance Systems. 2020. Available online: https://www.repa irerdrivennews.com/wp-content/uploads/2022/02/E.1.-Research-Report-Evaluating-ADA-FINAL-7-13-20.pdf (accessed on 13 February 2022).

18. Society of AutomotiveEngineers (SAE). SAE J3016 Taxonomy and Definitions for Terms Related to Driving Automation Systems for On-Road Motor Vehicles RATIONALE. 2021. Available online: https://www.sae.org/standards/content/j3016_202104/ (accessed on 13 February 2022).

19. Xiaoxia Baidu Tests Driverless Cars on Expressway in Shanxi. Available online: http://www.xinhuanet.com/english/2019-01/ 23/c_137768368.htm (accessed on 13 February 2022).

20. Union Internationale des Transports Publics Shared Personalised Automated Connected vEhicles (SPACE): SmartShuttle. Available online: https:/ /space.uitp.org/initiatives/smartshuttle-sion-av-switzerland (accessed on 13 February 2022).

21. MOVECIT. Guidelines for Developing a Mobility Plan. 2017. Available online: https://www.interreg-central.eu/Content.Node /Movecit/Guidelines-for-developing-mobility-plan.pdf (accessed on 13 February 2022).

22. Capital Region Planning Commission. Surface Transportation Block Grant Program Project Scoring Guide. 2017. Available online: https: / / www.fhwa.dot.gov/specialfunding/stp/ (accessed on 13 February 2022).

23. Buhrmann, S.; Wefering, F.; Rupprecht, S. Guidelines for Developing and Implementing a Sustainable Urban Mobility Plan 2nd Edition. 2019. Available online: https:/ / www.eltis.org/mobility-plans/sump-guidelines (accessed on 2 February 2022).

24. Federal Highway Administration (FHWA). Highway Functional Classification Concenpts, Criteria and Procedures. 2013. Available online: https:/ / dot.sd.gov/media/documents/HwyFunctionalClassification.pdf (accessed on 13 February 2022).

25. Paraphantakul, C. Review of Worldwide Road Classification Systems. In Proceedings of the 9th National Transportation Conference, Bangkok, Thailand; 2014; pp. 20-21.

26. Tak, S.; Kim, H.; Kang, K.; Lee, D. A Study on the Introduction for Automated Vehicle-based Mobility Service Considering the Level Of Service of Road Infrastructure. J. Korea Inst. Intell. Transp. Syst. 2019, 18, 19-33. [CrossRef]

27. The Korea Expressway Corporation Expressway Data. Available online: http:/ / data.ex.co.kr (accessed on 13 February 2022).

28. Federal Highway Administration. Road Safety Information Analysis:A Manual for Local Rural Road Owners. 2011. Available online: https://safety.fhwa.dot.gov/local_rural/training/fhwasa1210/lrro_data.pdf (accessed on 13 February 2022).

29. Molugaram, K.; Rao, G.S.; Shah, A.; Davergave, N. Statistical Techniques for Transportation Engineering; ButterworthHeinemann. 2017. Available online: https://www.sciencedirect.com/book/9780128115558/statistical-techniques-for-transporta tion-engineering (accessed on 2 February 2022).

30. De'ath, G.; Fabricius, K.E. Classification and regression trees: A powerful yet simple technique for ecological data analysis. Ecology 2000, 81, 3178-3192. [CrossRef]

31. Cong, C.; Tsokos, C. Theory and applications of decision tree with statistical software. Age 2009, 58, 250.

32. Pappalardo, G.; Cafiso, S.; Di Graziano, A.; Severino, A. Decision tree method to analyze the performance of lane support systems. Sustainability 2021, 13, 846. [CrossRef]

33. Kotu, V.; Deshpande, B. Predictive Analytics and Data Mining: Concepts and Practice with Rapidminer; Morgan Kaufmann. 2014. Available online: https:/ / www.sciencedirect.com/book/9780128014608/predictive-analytics-and-data-mining (accessed on 2 February 2022).

34. Elvik, R. International transferability of accident modification functions for horizontal curves. Accid. Anal. Prev. 2013, 59, 487-496. [CrossRef]

35. Zegeer, C.V.; Stewart, J.R.; Council, F.M.; Reinfurt, D.W.; Hamilton, E. Safety effects of geometric improvements on horizontal curves. Transp. Res. Rec. 1992, 1356, 11-19.

36. Hang, Z.; Teng, S. Influence of Traffic Safety on Road Alignment Design. In Proceedings of the ICTIS 2011: Multimodal Approach to Sustained Transportation System Development: Information, Technology, Implementation, Wuhan, China, 30 June-2 July 2011 ; pp. 1280-1285.

37. Khoury, J.; Amine, K.; Abi Saad, R. An initial investigation of the effects of a fully automated vehicle fleet on geometric design. J. Adv. Transp. 2019, 2019. [CrossRef]

38. Wang, S.; Yu, B.; Ma, Y.; Liu, J.; Zhou, W. Impacts of different driving automation levels on highway geometric design from the perspective of trucks. J. Adv. Transp. 2021, 2021, 5541878. [CrossRef]

39. Turoń, K.; Kubik, A.; Chen, F. When, What and How to Teach about Electric Mobility? An Innovative Teaching Concept for All Stages of Education: Lessons from Poland. Energies 2021, 14, 6440. [CrossRef] 